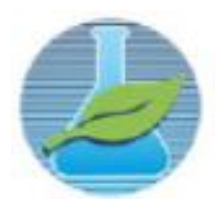

ol. 02 N. 04 (2016) 019-021
JCEC/REQ ${ }^{2}$

Journal

ISSN: 2446-9416

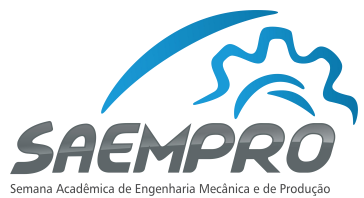

"EU, A INDÚSTRIA E O MUNDO"

08 a 11 de novembro de 2016 no campus Viçosa da UFV

Departamento de Engenharia de Produção e Mecânica - DEP

Universidade Federal de Viçosa - UFV

\title{
ESTUDO DE UM NOVO PERFIL AERODINÂMICO VOLTADO PARA A COMPETIÇÃO SAE BRASIL AERODESIGN
}

\author{
Hygor Vaz de Souza Barbosa \\ Universidade Federal de Viçosa, Departamento de Engenharia de Produção e Mecânica \\ Ph. Rolfs s/n - 36570-000 - Viçosa - MG \\ hygor.barbosa@ufv.br
}

\section{INTRODUÇÃO}

O projeto aerodinâmico e todo o estudo de fenômenos relacionado ao mesmo são de grande importância para o projeto final da aeronave, pois, segundo Rodrigues (2014), a configuração aerodinâmica adequada influencia na análise de estabilidade e desempenho da aeronave, assim como o projeto estrutural.

A equipe Skywards de aerodesign da Universidade Federal de Viçosa participa anualmente da competição SAE Aerodesign que tem como principal objetivo o de construir uma aeronave rádio controlada que deve cumprir os principais requisitos de voo delimitados pelo regulamento da competição.

Diante dos objetivos da equipe, torna-se necessário uma criteriosa análise aerodinâmica em busca do perfil adequado para a asa, uma vez que a asa é um dos fatores de grande importância na eficiência e no desempenho da aeronave. A proposta é criar um perfil que possua melhor desempenho aerodinâmico, priorizando inicialmente o coeficiente aerodinâmico $(\mathrm{cl} / \mathrm{cd})$, utilizando um coeficiente de sustentação (cl) elevado, objetivando pleitear uma diminuição no coeficiente de arrasto (cd), e um considerável coeficiente de momento $(\mathrm{cm})$. Este trabalho será focado em um estudo realizado a fim de melhorar o sistema aerodinâmico do projeto da equipe Skywards Aerodesign.

\section{METODOLOGIA}

O novo perfil, denominado SKW0001, foi desenvolvido seguindo as orientações de Barros (2001), que recomenda que a espessura relativa do perfil seja maior que $12 \%$ da corda do mesmo, favorecendo a aeronave quanto ao aumento da velocidade máxima horizontal e quanto ao pouso e decolagem devido ao alto coeficiente de sustentação $\left(\mathrm{CL}_{\max }\right)$.

$\mathrm{O}$ perfil foi desenvolvido utilizando o software XFLR5 ${ }^{\circledR}$ modelando as características necessárias para satisfazer o desempenho aerodinâmico almejado. No software utilizou-se de diversos perfis como base, que foram trabalhados sob regime de aperfeiçoamento, misturas de perfis e modificações diversas.

Além da análise feita pelo software XFLR $5^{\circledR}$, será realizado, posteriormente, um estudo mais detalhado pelo método computacional de fluidos dinâmicos (CFD) usando o software ANSYS Fluent $^{\circledR}$.

Por fim, será realizado um estudo experimental, utilizando um modelo em um túnel de vento à fim de validar os resultados computacionais.

\subsection{Pesquisa Teórica}


Conforme restrições analisadas em aeromodelos e conforme da teoria apresentada por Selig (1996), necessitamos de um aerofólio de baixa velocidade. Através da database de aerofólios feitos pela Universidade de Illinois em Urbana-Champaign os principais perfis de alta sustentação e baixo número de Reynolds são: E423, S1210, S1223, FX-63-137sm.

Propomos então que nosso perfil aerodinâmico deveria apresentar melhores características de coeficiente de sustentação, coeficiente de arrasto e eficiência aerodinâmica que os perfis apresentados por Selig (1996).

\section{RESULTADOS COMPUTACIONAIS}

Com o auxílio do software XFLR $5^{\circledR}$ analisou e comparou-se cinco perfis diferentes, baseados

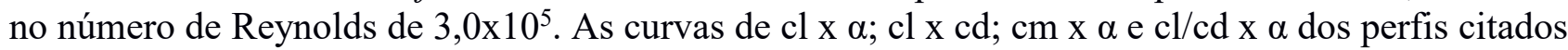
foram comparadas e representadas na Fig. 1.

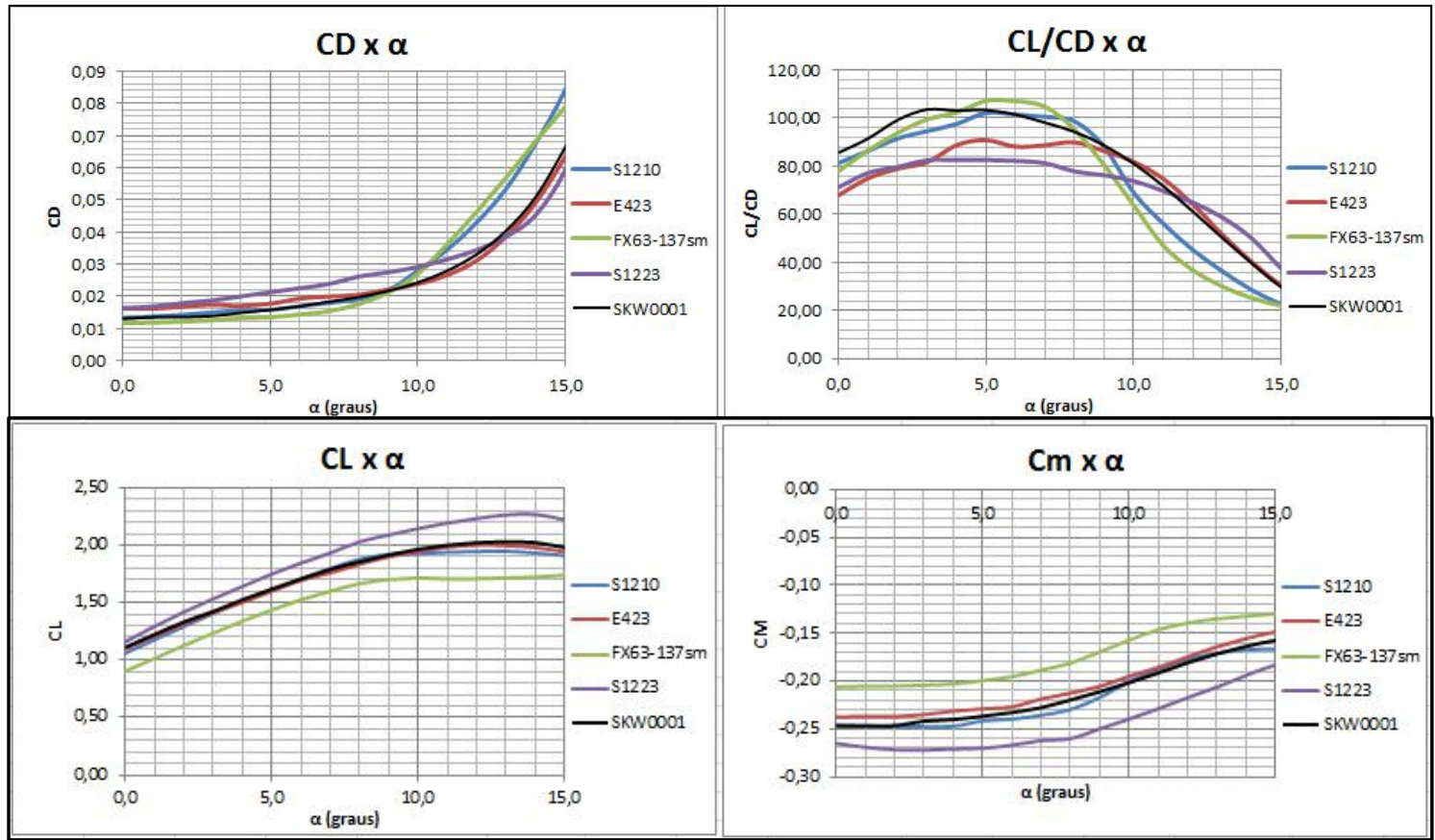

Figura 1 - Gráficos comparativos de coeficientes aerodinâmicos dos perfis de asa.

Com o auxílio dos gráficos acima, registrou-se na Tab. 1 os principais dados que influenciam na escolha do perfil.

Tabela 1 - Resultados obtidos com Reynolds de 3 x $10^{\wedge} 5$.

\begin{tabular}{|c|c|c|c|c|c|}
\hline Perfil & S1210 & E423 & FX63-137sm & S1223 & SKW0001 \\
\hline cl máx & 1,9474 & 2,0004 & 1,7713 & 2,2669 & 2,0313 \\
\hline cl/cd máx & 102,102 & 90,829 & 107,169 & 82,573 & 103,544 \\
\hline cm (alpha = 0) & $-0,2460$ & $-0,2377$ & $-0,2062$ & $-0,2650$ & $-0,2470$ \\
\hline cd (alpha = 0) & 0,01303 & 0,01618 & 0,01160 & 0,01627 & 0,01298 \\
\hline
\end{tabular}

Dispondo das informações da Tab. 1 e dos gráficos da Fig. 1 fez-se das presentes análises as seguintes conclusões. O Perfil SKW0001 apresenta uma boa curva de sustentação ao longo dos ângulos de inclinação, estando apenas abaixo da curva do perfil S1223. Pela Tabela 1, tem-se que SKW0001 apresenta o segundo maior $\mathrm{cl}_{\max }$. Outro fator relevante é o SKW0001 possui um cd0 menor do que o S1223. Mesmo que o perfil FX63-137sm possua o menor cd0, percebe-se pelo gráfico cd x alpha, que o comportamento do coeficiente de arrasto do perfil SKW0001 com a variação do ângulo se apresenta melhor do que o perfil FX63-137 sm. Analisando o gráfico cl/cd x alpha é perceptível que no ângulo 0, o perfil SKW0001 possui melhor desempenho. Também, possui um alto coeficiente 
aerodinâmico e menos oscilações e menos perdas de sustentação da trajetória de subida. Perfis como S1210 e FX62-137sm tem uma perda brusca no coeficiente aerodinâmico, após o ápice.

\section{CONSIDERAÇÕES FINAIS}

Conforme objetivado, após interações realizadas, observou-se que o perfil SKW0001 apresenta as características favoráveis para desempenhar os requisitos necessários, conforme apresentado nas análises de perfis. Visto que o perfil possui bom coeficiente de sustentação, baixo coeficiente de arrasto e de momento, e coeficiente aerodinâmico muito satisfatório. Entretanto, ainda é necessária a validação do modelo pelo método CFD e experimental.

\section{AGRADECIMENTOS}

Agradecemos o apoio da FAPEMIG por meio do Programa Santos Dumont no apoio ao desenvolvimento do projeto e a FUNARBE.

\section{REFERÊNCIAS}

SELIG, M.S., GUGLIELMO, J.J., BROEREN, A.P. and GIGUERE, P. "Summary of Low-Speed Airfoil Data", Virginia: SoarTech Publications, 1996.

RAYMER, D. P. "Aircraft Design: A Conceptual Approach". Third Edition AIAA - American Institute of Aeronautics and Astronautics, 1999.

BARROS, C.P. "Uma metodologia para o desenvolvimento de projeto de Aeronaves Leves $e$ Subsônicas." Tese (Doutorado) - departamento de Mecânica, UFMG, 2001.

Universidade de Illinois em Urbana-Champaign. Airfoil Coordinates Database. Departament of Aerospace Engineering. Disponível em: $<$ http://m-selig.ae.illinois.edu/ads/coord_database.html $>$ 